\title{
Predicting Bankruptcy After The Sarbanes- Oxley Act Using Logit Analysis
}

Wikil Kwak, University of Nebraska at Omaha, USA

Xiaoyan Cheng, University of Nebraska at Omaha, USA

Jinlan Ni, University of Nebraska at Omaha, USA

\begin{abstract}
Our study proposes firm bankruptcy prediction using logit analysis after the passage of the Sarbanes-Oxley (SOX) Act using 2008-2009 U.S. data. The results of our logit analysis show an $80 \%$ (90\% with one year before bankruptcy data) prediction accuracy rate using financial and other data from the 10-K report in the post-SOX period. This prediction rate is comparable to other data mining tools. Overall, our results show that, as compared to the prediction rates documented by other bankruptcy studies before SOX, firm bankruptcy prediction rates have improved since the passage of SOX. Our findings shed light on the benefits of SOX by providing evidence that legislation makes the financial reporting more informative. This study is important for regulators to implement public policy. Investors may be interested in our findings to better assess company risk when making portfolio decisions.
\end{abstract}

Keywords: Sarbanes-Oxley Act; Bankruptcy; Logit Analysis

\section{INTRODUCTION}

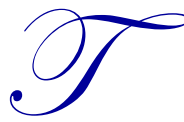

he Sarbanes-Oxley Act (SOX) of 2002 was introduced to require reporting on the effectiveness of any material weaknesses in internal controls over financial reporting by a firm's top CEOs and accountants. The objective of SOX is to enhance the reliability of financial statements. Therefore, SOX will improve the quality of financial reporting and deter corporate fraud in the U.S.; however, opponents have been concerned that the costs of implementing the provisions of SOX may outweigh the benefits. This issue of costs and benefits of the SOX effect is still a controversial issue as the SEC recently excluded the implementation of SOX for small firms with sales less than 75 million (Solnik, 2010).

One major benefit of SOX is the improvement of financial reporting quality, thereby enabling investors or other decision makers to sort out good and bad companies. In this study, we examine firm bankruptcy after the passage of SOX and compare the overall prediction accuracy rates with those of general bankruptcy studies before SOX. We use logit analysis in this study because it enables us to identify the specific variables that contribute to bankruptcy prediction. Based on the logit model, we find an $80 \%$ (90\% with one year before bankruptcy data) prediction accuracy rate using financial and other data from the 10-K report after SOX. This prediction rate is comparable to other data mining tools. Overall, our results show that, compared with other previous logit bankruptcy studies, firm bankruptcy prediction rates improved after the passage of SOX.

This paper adds to a growing body of research that documents the benefits of SOX. Evidence on the bankruptcy prediction accuracy is likely to be of interest to standard setters. The improved accuracy in predicting firm bankruptcy after the passage of SOX helps investors better evaluate the distress risk of companies when making portfolio decisions. In this sense, the findings of this study have implications in making investment decisions.

The next section presents the background and prior research relevant to our study, followed by a section describing our sample data and reports our empirical results, and concluding with a summary of our findings and future research avenues. 


\section{BACKGROUND AND PRIOR RESEARCH}

SOX was introduced to minimize financial fraud and reestablish investor confidence after major scandals such as Enron and Worldcom at the turn of century, but after another market crash in 2008, investors doubted the true impact of SOX. The benefits of SOX are supposed to improve corporate governance mechanisms and improve the quality of financial reporting for investors. However, costs of SOX are not trivial for small firms and the SEC finally excluded small firms from the SOX implementation. SOX was fully implemented in the U.S. in 2008 for medium or large firms and our study tries to measure the benefits of SOX using the firm bankruptcy study context.

There are two types of errors (Type-I and Type-II) involved in general prediction studies like ours. Type-I error refers to false rejection error. For example, in a bankruptcy prediction study, we reject the null hypothesis that a firm is a non-bankrupt firm even though the firm is actually a bankrupt firm. This type of error will be very costly for a decision maker. A Type-II error is the opposite case. For example, we predict a firm to be a bankrupt firm, even though the firm is not a bankrupt firm. In the Type-II error case, the cost of misclassification is not as severe as in the Type-I error case. For our study, we focus on overall prediction accuracy and Type-I errors because the cost of misclassifying can be significant.

Altman (1968) originally used multiple discriminant analysis (MDA) by using five financial ratios to predict firm bankruptcy using a manufacturing sample and matching control firms. Ohlson (1980) later used a logit model that does not require any assumptions about the prior probability of the bankruptcy sample. However, as Grice and Dugan (2001) later pointed out, hold-out sample tests are potentially upwardly biased. Platt and Platt (1990) also suggested that the differences in the macro economic factors are sensitive to specific time periods. Therefore, Grice and Ingram (2001) empirically tested and reported that Altman's (1968) study using a small sample of 33 manufacturing firms and the use of an equal sample size of bankrupt and non-bankrupt firms using a sample from 1958 to 1961 reported 83.5\% overall accuracy. However, Altman's model using the 1988-1991 test period showed that the overall correct classification rate dropped to 57.8\%. Begley et al. (1996) also reestimated both Altman's (1968) and Ohlson's (1980) models using 1980 data and reported that Ohlson's model showed a Type-I error rate of $29.2 \%$ and a Type-II error rate of $14.9 \%$ at the cutoff point of 0.061 . They suggested that both models' accuracy rates drop as they are applied in different time periods, but Ohlson's model is a preferred model because it does not require any assumptions about the prior probability of bankruptcy sample. In our study we also want to compare both models after the passage of SOX to test this issue.

Goal programming (GP) was proposed by Freed and Glover (1986) to minimize misclassifications of TypeI and Type-II errors. However, the GP approach is not practical because of computational problems around that time (Koehler and Erenguc, 1990).

Shumway (2001) proposed a simple hazard model to be better for bankruptcy prediction studies like ours, but we do not have longitudinal data to apply his model and we decided to use the traditional logit model for this study to check which variables are contributing to bankruptcy prediction.

Recently, several researchers had compared machine learning, neural networks, case-based reasoning, and statistics approaches using experiments to predict bankruptcy, but their results are not conclusive as to which methods outperform the other methods (see, Sung et al., 1999, Yip, 2006 and Peng et al., 2009, for example). Rough sets theory is also proposed because a cause-effect relationship between factors and the actual occurrence of bankruptcy is not easy (McKee, 2000), but empirical study showed $61 \%$ and $68 \%$ accuracy rates using this theory (McKee, 2003). Duffie et al. (2007) proposed a multi-period bankruptcy model would be better using large sample firms. Generally, bankruptcy prediction rates around $85 \%$ are acceptable and some data mining method prediction rates are context specific.

\section{SAMPLE DATA, VARIABLES, AND EMPIRICAL RESULTS}

In this paper, we used the data search engine DirectEDGAR (2008) to identify 35 (130 for three-year data) firms that filed bankruptcy in 2008 and 2009. Next, we collected more than double the number of matching control firms based on firm size and the two-digit industry codes that had no bankruptcy filing to emulate the real world 
context. We started with more than double the number of control firms, because the three years of financial data for some firms are not available and these control firms are excluded from further analyses. Our final control firms are composed of 306 firm-year observations for the three years that have available financial and other data in Form 10$\mathrm{K}$ filings using DirectEDGAR and Compustat.

In selecting variables that may help predict firm bankruptcy after SOX, we included Altman et al.'s (1968) variables and Ohlson's (1980) variables because these variables have proven to be useful in bankruptcy prediction studies.

First, we run our logit model using five variables as Altman (1968) did in his study.

Bankruptcy (1), otherwise $(0)=\alpha_{0}+\Sigma \beta$ Altman's five ratios $(X 1, \ldots \ldots, X 5)+\varepsilon$

X1 =Working capital divided by total assets (WCA_TA)

$\mathrm{X} 2=$ Retained earnings divided by total assets (RE_TA)

$\mathrm{X} 3=$ Earnings before interest and taxes divided by total assets (EBIT_TA)

$\mathrm{X} 4$ = Market value of equity divided by book value of total debt (MKV_TD)

$\mathrm{X} 5=$ Sales divided by total assets (SALES_TA)

The ratio of working capital to total assets $\left(W C A \_T A\right)$ is a proxy for firm liquidity. The working capital ratio measures the ability of a company to pay its incoming debt. The lower the working capital, the higher the possibility of being bankrupt. The ratio of retained earnings to total assets $\left(R E_{-} T A\right)$ captures the extent to which assets have been paid for by cumulative profits. Altman (1968) finds that younger firms have a higher risk of bankruptcy than older firms due to a lack of time to build up cumulative profits. Earnings before interest and taxes, scaled by total assets (EBIT_TA), is used to measure operating efficiency apart from any tax and leveraging factors. This is an important predictor of firm bankruptcy, given the fact that a firm's existence depends on the earning power of its assets. We use market value of equity, divided by book value of total debt $\left(M K V_{-} T D\right)$, to proxy for firm leverage. A low equity/debt ratio increases the risk of insolvency. Finally, asset turnover ratio, defined as sales divided by total assets (SALES_TA), is included to evaluate the firms' effectiveness in managing assets. The higher the assets turnover ratio, the better the management's capability to generate revenues.

Next, we run our model using Ohlson's (1980) nine variables.

Bankruptcy (1), otherwise $(0)=\alpha_{0}+\Sigma \beta$ Ohlson's nine ratios $(Y 1, \ldots \ldots, Y 9)+\varepsilon$

Y1: Size, measured as the logarithm of total Assets (SIZE)

Y2: Total liabilities divided by total assets (TL_TA)

Y3: Working capital divided by total assets (WCA_TA)

Y4: Total current liabilities divided by total current assets (CL_CA)

Y5: Net income divided by total assets (NI_TA)

Y6: If TL_TA $>1$ then OENEG=1; else OENEG=0

Y7: Funds from operations divided by total liabilities (FU_TL)

Y8: If Net Income $<\mathbf{0}$ or lag (Net Income) $<\mathbf{0}$ then INTWO $=\mathbf{1}$; else INTWO=0

Y9: $\mathrm{CHIN}=($ Net Income- lag (Net Income) $) /$ [absolute (Net Income) + absolute (lag Net Income) $]$

As documented by Ohlson (1980), smaller firms (SIZE), firms with higher financial leverage (TL_TA), firms with current liquidity problems (lower $W C A \_T A$ and/or higher $C L_{-} T A$ ), and firms with poorer performance measures (NI_TA and/or $\left.F U_{-} T L\right)$ increase the likelihood of business failure.

In addition to the above bankruptcy prediction variables, we included internal control weakness, stock market return, and dividend missing variables. These variables were useful in firm bankruptcy prediction in previous studies (see, Sun, 2007; Hammersley, et al. 2008, for example). However, our sample firms near bankruptcy stage are missing most of the return data. 
Table 1 shows the descriptive statistics. As shown, all variables between bankrupt firms and non-bankrupt firms are significantly different except for Size (SIZE), Funds from operations/Total liabilities (FU_TL), Changes in income/Average Income of two years (CHGREIN), firm's Market value of equity/Total debts (MKV_TD), Sales/Total assets (SALES_TA), and Annual market return data (RET). Size is not supposed to be different as we matched control firms based on total assets. Annual market return data are not significant because of a lot of missing data for bankrupt firms. As we matched based on size and industry, bankrupt firms and non-bankrupt Market value of equity/Total debts and Sales/Total assets are similar as we expected. For one-year data, the results are similar except Funds from operation/Total liabilities and Market return data are marginally significant compared with 3-year data and not reported for brevity. However, Total liabilities/Total assets $>1$ ratio is not significant. In addition, Earning before interest and taxes/Total assets and Internal control weakness variables are marginally significant.

Table 1: Descriptive Statistics With Firm Year Data

\begin{tabular}{|c|c|c|c|c|c|c|}
\hline \multicolumn{7}{|l|}{ Bankrupt =1 } \\
\hline Variable & $\mathbf{N}$ & Mean & Std Dev & Minimum & Maximum & t-stat (1) \\
\hline SIZE & 130 & 3.036 & 0.670 & 1.067 & 4.251 & 1.88 \\
\hline TDEBT_TA & 130 & 0.522 & 0.373 & 0.000 & 2.365 & $6.54 * * *$ \\
\hline WCA_TA & 130 & 0.004 & 0.366 & -2.356 & 0.574 & $-5.30 * * *$ \\
\hline CL_CA & 130 & 1.325 & 1.917 & 0.139 & 13.667 & $3.46 * * *$ \\
\hline NI_TA & 130 & -0.128 & 0.238 & -1.367 & 0.544 & $-4.99 * * *$ \\
\hline FU_TL & 130 & 33.568 & 347.968 & -52.720 & 3949.740 & -0.70 \\
\hline LOSS & 130 & 0.815 & 0.389 & 0.000 & 1.000 & $11.59 * * *$ \\
\hline OENEG & 130 & 0.085 & 0.279 & 0.000 & 1.000 & $2.98 * *$ \\
\hline CHGREIN_TA & 130 & -3.045 & 27.966 & -198.828 & 110.229 & -1.24 \\
\hline EBIT_TA & 130 & -0.014 & 0.131 & -0.924 & 0.171 & $-5.49 * * *$ \\
\hline MKV_TD & 130 & 42.646 & 410.251 & 0.000 & 4648.890 & -1.35 \\
\hline SALES_TA & 130 & 1.235 & 0.858 & 0.016 & 4.439 & 1.82 \\
\hline RE_TA & 130 & -0.593 & 1.168 & -7.327 & 0.470 & $-5.04 * * *$ \\
\hline $\mathrm{IC}$ & 130 & 0.208 & 0.407 & 0.000 & 1.000 & $4.71 * * *$ \\
\hline DIV & 128 & 0.758 & 0.430 & 0.000 & 1.000 & $3.38 * * *$ \\
\hline RETX & 28 & -0.489 & 0.938 & -2.371 & 1.086 & -1.84 \\
\hline \multicolumn{7}{|l|}{ Bankrupt $=0$} \\
\hline Variable & $\mathbf{N}$ & Mean & Std Dev & Minimum & Maximum & \\
\hline SIZE & 306 & 2.899 & 0.768 & -0.220 & 5.301 & \\
\hline TDEBT_TA & 306 & 0.292 & 0.229 & 0.000 & 1.080 & \\
\hline WCA_TA & 306 & 0.186 & 0.215 & -0.670 & 0.824 & \\
\hline CL_CA & 306 & 0.728 & 0.681 & 0.093 & 9.785 & \\
\hline NI_TA & 306 & -0.006 & 0.219 & -2.188 & 0.589 & \\
\hline FU_TL & 306 & 83.021 & 1119.380 & -78.358 & 19433.310 & \\
\hline LOSS & 306 & 0.314 & 0.465 & 0.000 & 1.000 & \\
\hline OENEG & 306 & 0.010 & 0.099 & 0.000 & 1.000 & \\
\hline CHGREIN_TA & 304 & 0.004 & 0.068 & -0.248 & 0.365 & \\
\hline EBIT_TA & 306 & 0.071 & 0.182 & -2.160 & 0.889 & \\
\hline MKV_TD & 306 & 386.955 & 4421.000 & 0.002 & 75722.150 & \\
\hline SALES_TA & 306 & 1.081 & 0.668 & 0.080 & 3.137 & \\
\hline RE_TA & 306 & -0.013 & 0.919 & -11.439 & 1.558 & \\
\hline $\mathrm{IC}$ & 306 & 0.033 & 0.178 & 0.000 & 1.000 & \\
\hline DIV & 306 & 0.598 & 0.491 & 0.000 & 1.000 & \\
\hline RETX & 212 & -0.153 & 0.644 & -4.071 & 1.608 & \\
\hline
\end{tabular}

${ }^{(1)}$ t-value for testing mean differences between bankrupt and non-bankrupt firms

${ }^{*}: \mathrm{p}<0.10$

**: $\mathrm{p}<0.05$

$: \mathrm{p}<0.001$

Variable Descriptions:

Size $\quad=$ the $\log$ of total assets

TDEBT_TA = total debt divided by total assets (Ohlson 1980 ratio)

WCA_TA = working capital divided by total assets (Altman 1968 ratio and Ohlson 1980 ratio) 


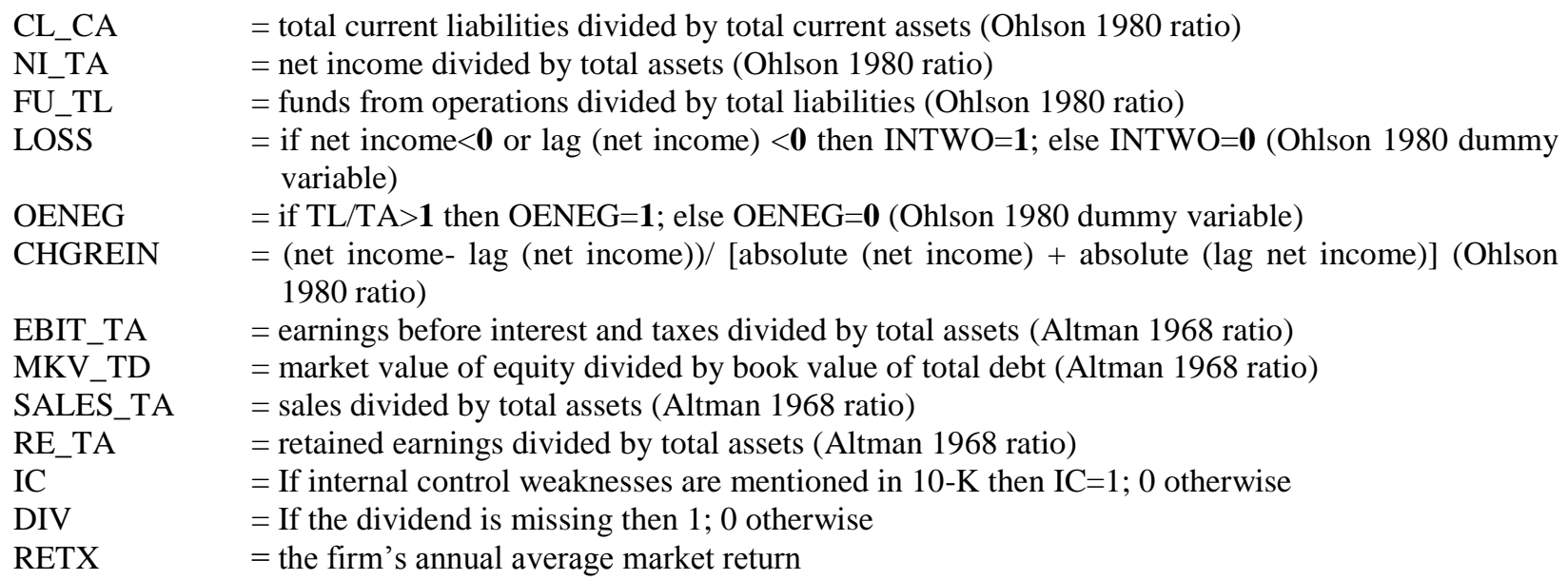

Table 2 presents our results using Altman's (1968) five ratios. This model is significant as maximum rescaled R-square is 22\%, Likelihood Chi-Square is 73.61, and Wald's Chi-Square is 42.93 and significant at less than .001 . The overall prediction rate is $75 \%$ (one-year data prediction rate is $83 \%$ and not reported here) and this rate is comparable with that of a similar data mining bankruptcy study by Kwak et al. (2012). Not surprisingly, we find that the coefficient on $M K V_{-} T D$ (market value of equity divided by total debts) is not significant given that as shown in Table 1. MKV_TD is not significantly different between bankrupt and non-bankrupt firms. The result indicates market value of a firm is not important for bankruptcy prediction.

Table 2: Logit Regression Analysis Using Altman's Five Predictor Variables With 3-Year Data $(\mathbf{N}=436)$

\begin{tabular}{|c|c|c|c|c|}
\hline Parameter & Estimate & Standard Error & Wald Chi-Square & Pr $>$ ChiSq \\
\hline Intercept & -1.1077 & 0.2231 & 24.6579 & $<.0001$ \\
\hline EBIT_TA & -2.4221 & 1.1390 & 4.5220 & 0.0335 \\
\hline MKV_TD & -0.00081 & 0.000835 & 0.9408 & 0.3321 \\
\hline SALES_TA & 0.5399 & 0.1640 & 10.8338 & 0.0010 \\
\hline WCA_TA & -2.6565 & 0.6335 & 17.5862 & $<.0001$ \\
\hline RE_TA & -0.3393 & 0.1724 & 3.8724 & 0.0491 \\
\hline $\begin{array}{l}\text { Likelihood Chi-Square } \\
\text { Wald's Chi-Square } \\
\text { Max-rescaled R-Square } \\
\text { Overall prediction rate }\end{array}$ & & & & \\
\hline
\end{tabular}

Variables are defined in Table 1.

Table 3 presents logit analysis results with Ohlson's (1980) nine-variable model. Overall, this model is significant as the maximum rescaled R-square is 37\%, Likelihood Chi-Square is 131.35, and Wald's Chi-Square is 86.84 and significant at less than .001 . The overall prediction rate is $77 \%$ (one-year prediction rate is $84 \%$ and not reported here). As expected, the prediction rate of Ohlson's (1980) model is 2\% higher than Altman's (1968) model. However, variables CL_CA (current liabilities divided by current assets), FU_TL (funds from operation divided by total liabilities), and $\mathrm{OENEG}$ (if $\mathrm{TL} / \mathrm{TA}>1$ then $\mathrm{OENEG}=1$; else $\mathrm{OENEG}=0$ ) are not significant in predicting business failure. 
Table 3: Logit Analysis Using Ohlson's Nine Predictor Variables With 3-Year Data (N=434)

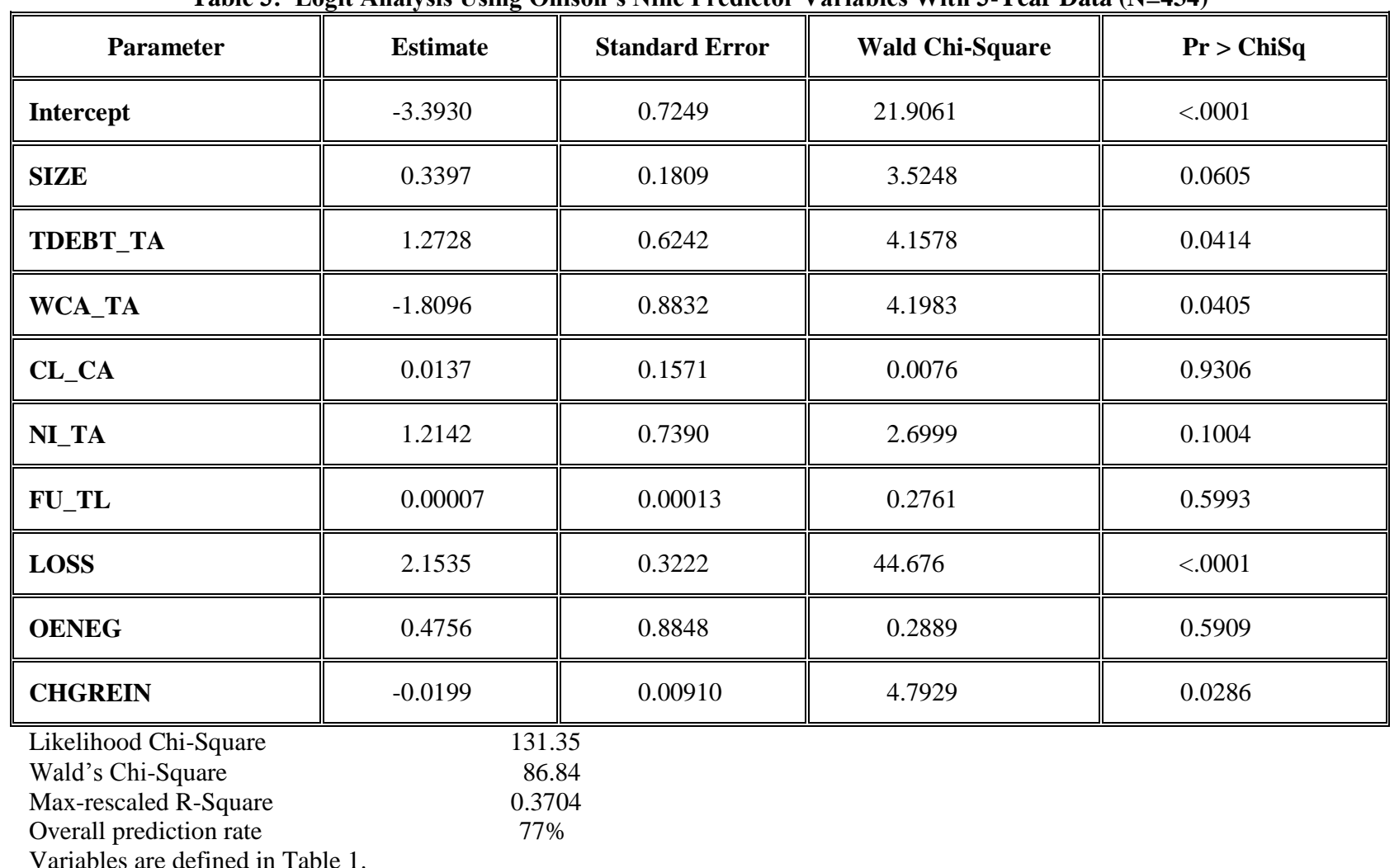

Table 4 presents the combined variable model and maximum-scaled R-square as $45.38 \%$. Likelihood ratio and Wald test show 167.36 and 93.91, respectively, and significant at less than .001. The overall prediction rate is $80 \%$ (one-year prediction rate is $90 \%$ and not reported here) for this model. We conclude the logit model performs better consistently as firms approach near bankruptcy stage. Size is not significant as we expected. Similar to the results presented in each individual model, we find that CL_CA (current liabilities divided by current assets), FU_TL (funds from operation divided by total liabilities), OENEG (if TL/TA>1 then OENEG=1; else OENEG=0), and MKV_TD (Market value of equity divided by total debts) are not significant at the conventional levels.

Table 5 reports the combined model with other variables proven to be significant in previous bankruptcy prediction studies. Maximum-rescaled R-square is 57.6\% and Likelihood ratio and Wald test are 84.16 and 33.00, respectively, and significant at the .01 level. The overall prediction rate is $73.9 \%$ (one-year prediction rate is 81.7\%). This is not surprising because we lose a lot of data entered in the analysis. Interestingly, the internal control variable is significant at the .05 level and the dividend missing variable is marginally significant. However, the market return variable is not significant because of missing values of near-bankrupt firms. Each variable contributing to the overall model is consistent with previous model, except that NI_TA (Net income divided by total assets) and EBIT_TA (Earnings before interest and taxes divided by total assets) variables are not significant.

Most of the bankruptcy predictors are strongly correlated with each other. The high correlation raises the problem of multicollinearity. Although multicollinearity does not decrease the predictive power of the model as a whole, the regression coefficients may be biased and, therefore, we are unable to determine the attributes that are associated with bankruptcy. To address the issue of multicollinearity, we perform a principal component factor analysis. The factor analysis reduces a set of observable variables to a small number of factors. The extracted common factors reflect the underlying dimensions of the economic determinants of firm bankruptcy. Following the Kaiser (1960) rule, we retain all factors with eigenvalues greater than one. This process gives us three factors. Table 6 Panel A shows that the three factors explain 91 percent of the total variance in the data with the combined Altman (1968) and Ohlson (1980) variables. Then the reduced three factors are rotated using an oblique rotation. The 
oblique rotation allows the factors to be correlated with each other. In our case, the correlations among the three factors are less than 0.1 , suggesting the extracted three factors are essentially orthogonal.

Table 4: Combination Of Altman's And Ohlson's Predictor Variables With 3-Year Data (N=434)

\begin{tabular}{|c|c|c|c|c|}
\hline Parameter & Estimate & Standard Error & Wald Chi-Square & Pr $>$ ChiSq \\
\hline Intercept & -4.1255 & 0.8076 & 26.0972 & $<.0001$ \\
\hline SIZE & 0.2507 & 0.2200 & 1.2983 & 0.2545 \\
\hline TDEBT_TA & 2.0512 & 0.7157 & 8.2144 & 0.0042 \\
\hline WCA_TA & -1.9557 & 0.9582 & 4.1660 & 0.0412 \\
\hline CL_CA & 0.0164 & 0.1545 & 0.0112 & 0.9156 \\
\hline NI_TA & 3.4068 & 0.9847 & 11.9695 & 0.0005 \\
\hline FU_TL & 0.0057 & 0.007 & 0.6670 & 0.4141 \\
\hline LOSS & 2.0999 & 0.3523 & 35.5363 & $<.0001$ \\
\hline OENEG & 0.2250 & 0.9080 & 0.0614 & 0.8043 \\
\hline CHGREIN & -0.0218 & 0.0098 & 4.8856 & 0.0271 \\
\hline EBIT_TA & -3.7374 & 1.4830 & 6.3510 & 0.0117 \\
\hline MKV_TD & -0.0033 & 0.0052 & 0.4124 & 0.5208 \\
\hline SALES_TA & 0.8328 & 0.2230 & 13.9498 & 0.0002 \\
\hline RE_TA & -0.2400 & 0.1679 & 2.0442 & 0.1528 \\
\hline $\begin{array}{l}\text { Likelihood ra } \\
\text { Wald's Chi-S } \\
\text { Max-rescaled } \\
\text { Overall predic }\end{array}$ & e & & & \\
\hline
\end{tabular}

Variables are defined in Table 1.

To interpret the factors, we examine the association between the combined Altman (1968) and Ohlson (1980) variables and each factor. We link each factor with those variables when the coefficient of each factor loading is greater than 0.4 in absolute value and is significantly different from zero at conventional levels. Table 6 Panel B presents the association between each factor and the resulting variables. The first factor explains $47 \%$ of total variation in the four variables, with loadings for LOSS, NI_TA, EBIT_TA, and RE_TA of $-0.55,0.70,0.86$, 0.79 , and 0.74 , respectively. Variables WCA_TA, TDEBT_TA, and CL_TA load strongly on the second factor, with loadings of $0.91,-0.61$, and -0.69 , respectively. The third factor has two variables, FU_TL and MKV_TD, with loadings of 0.88 and 0.75 , respectively. Based on the characteristics of the variables that are related to each factor, we conclude that factor 1 captures the notion of firm profitability. The higher value of factor 1 implies higher net income and hence higher retained earnings. Factor 2, on the other hand, seems to capture the notion of firm liquidity. The higher value of factor 2 suggests a larger margin of safety where the company is able to cover its debts. Finally, factor 3 appears to capture firm financial leverage. 
Table 5:Combination Of Altman's And Ohlson's Models With Other Control Variables

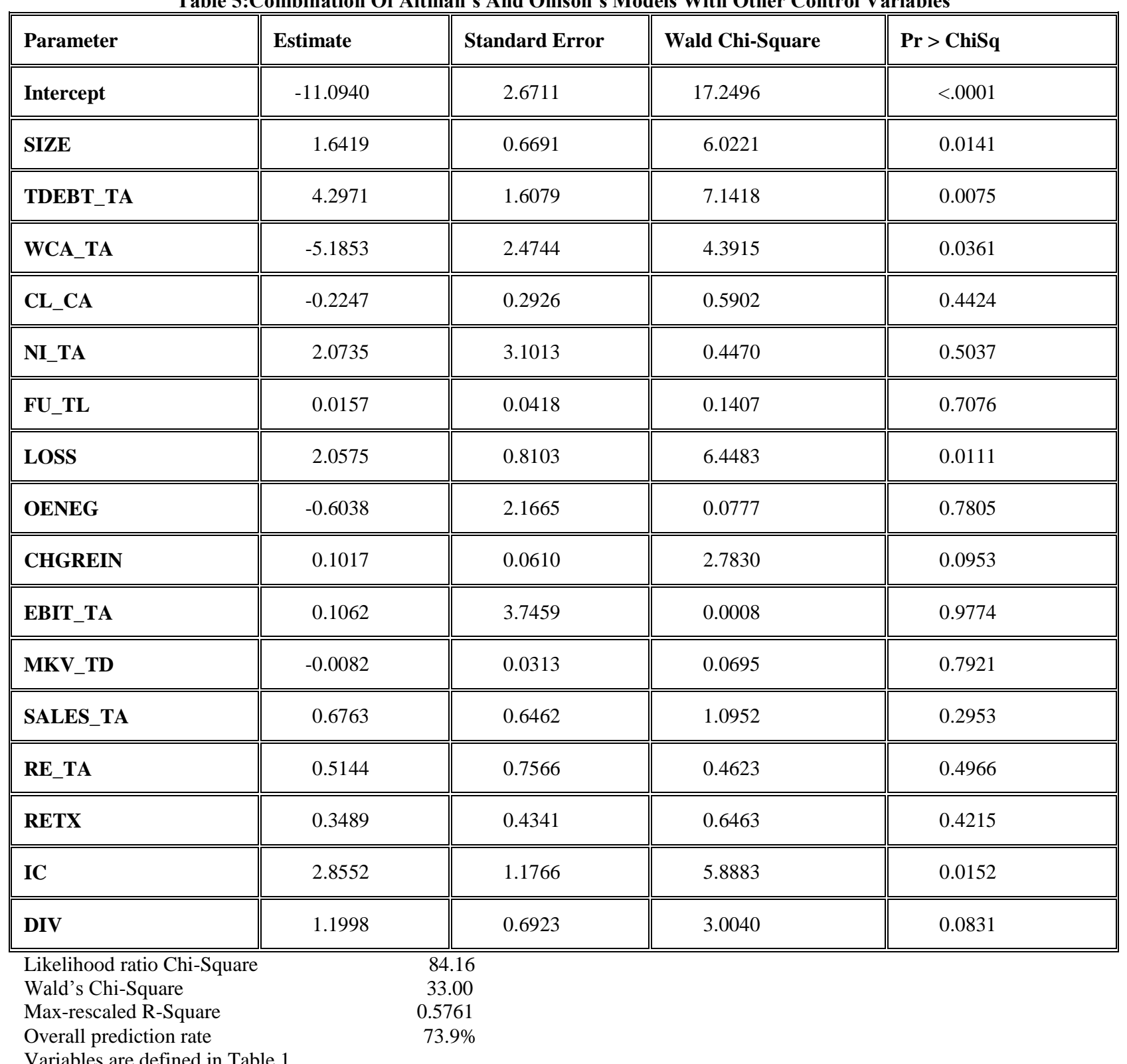

Table 6 Panel $\mathrm{C}$ shows the regression results using the extracted common factors. This model is significant as maximum rescaled R-square is $31.87 \%$. The likelihood Chi-Square is 83.75 and Wald's Chi-Square is 51.62. We find that the coefficients on factor 1 and factor 2 are significantly negative, suggesting that firms with poorer performances and firms with liquidity problems have a higher incidence of bankruptcy. However, factor 3 is insignificant in predicting business failure. The overall prediction rate is $75.8 \%$ with three-year data and $83.4 \%$ with one-year data. In short, the results presented in Table 6 Panel $\mathrm{C}$ suggest the extracted factors affect the accuracy of bankruptcy prediction. 
Table 6: Factor Analysis: Combination Of Altman's And Ohlson's Models

Panel A: Component Factors

\begin{tabular}{|c|c|c|c|}
\hline Factor & Eigenvalue & Percentage Explained & Cumulative Percentage \\
\hline 1 & 3.47 & 0.47 & 0.47 \\
\hline 2 & 1.98 & 0.27 & 0.74 \\
\hline 3 & 1.25 & 0.17 & 0.91 \\
\hline
\end{tabular}

Panel B: Component Loading Analysis

\begin{tabular}{|l|c|}
\hline \multicolumn{1}{|c|}{ Factor } & Component Loading \\
\hline Factor 1 (Profit) & -0.55 \\
\hline LOSS & 0.86 \\
\hline NI_TA & 0.79 \\
\hline EBIT_TA & 0.74 \\
\hline RE_TA & \\
\hline Factor 2 (Liquidity) & 0.91 \\
\hline WCA_TA & -0.61 \\
\hline TDEBT_TA & -0.69 \\
\hline CL_TA & \\
\hline Factor 3 (Leverage) & 0.88 \\
\hline FU_TL & 0.75 \\
\hline MKV_TD & \\
\hline
\end{tabular}

Panel C: Association Between Extracted Factors And The Likelihood Of Bankruptcy

\begin{tabular}{|l|c|c|c|c|}
\hline \multicolumn{1}{|c|}{ Parameter } & Estimate & Standard Error & Wald Chi-Square & Pr $>$ ChiSq \\
\hline Intercept & -1.7302 & 0.1977 & 76.607 & $<.0001$ \\
\hline Factor1 & -0.5818 & 0.1582 & 13.52 & 0.0002 \\
\hline Factor 2 & -0.5826 & 0.2032 & 8.2252 & 0.0041 \\
\hline Factor3 & -0.00005 & 0.00014 & 0.1246 & 0.7241 \\
\hline
\end{tabular}

$\begin{array}{lr}\text { Likelihood ratio Chi-Square } & 83.75 \\ \text { Wald's Chi-Square } & 51.62 \\ \text { Max-rescaled R-Square } & 0.3187 \\ \text { Overall prediction rate } & 75.8 \% \\ \text { Variables are defined in Table 1. } & \end{array}$

Finally, we conduct a supplementary factor analysis with the combined model and other control variables, such as internal control weakness, stock market return, and dividends. We find qualitatively similar results as Table 6. Untabulated results show that the loadings of these control variables are less than 0.20 in absolute value, suggesting that the control variables have insignificant associations with the extracted factors. Taken together, our factor analysis provides consistent results on the determinants in predicting firm bankruptcy based on past financial data.

\section{SUMMARY AND CONCLUSIONS}

Our findings will justify the benefits of SOX and it will be important for regulators for implementing public policy. Investors may be interested in our findings to better assess the distress risk of companies when they make portfolio decisions. It is still a controversial issue that benefits of SOX will improve the quality of corporate financial reporting and enhance investor confidence, but costs of compliance are not trivial. In this paper, we used logit analysis to predict bankruptcy after SOX using 2008-2009 data. The results of our logit analysis in bankruptcy prediction study show $80 \%$ accuracy rate $(90 \%$ for one year before bankruptcy data) and is comparable with other data mining approaches.

Our paper has several limitations. We only have a small sample of bankrupt firms and most market return data are missing. Another limitation is that bankrupt firms and non-bankrupt firms are heterogeneous and their actual probabilities of bankruptcy are non-observable (Baixauli and Modica-Milo, 2010). We may need other variables to improve the overall prediction accuracy and minimize the type-I error rate. 


\section{AUTHOR INFORMATION}

Wikil Kwak, University of Nebraska at Omaha. E-mail: wkwak@mail.unomaha.edu (Corresponding author)

Xiaoyan Cheng, University of Nebraska at Omaha. E-mail: xiaoyanchen1 @ unomaha.edu

Jinlan Ni, University of Nebraska at Omaha. E-mail: jni@unomaha.edu

\section{REFERENCES}

1. Altman E., Financial Ratios, Discriminant Analysis and the Prediction of Corporate Bankruptcy, Journal of Finance (September 1968), 589-609.

2. Begley, J. J Ming, and S. Watts, Bankruptcy Classification Errors in 1980s: An Empirical Analysis of Altman's and Ohlson's Models, Review of Accounting Studies 1, (1996), 267-284.

3. Baixauli, J. S. and Modica-Milo, A. The bias of unhealthy SMEs in bankruptcy prediction models, Journal of Small Business and Enterprise Development 17.1, (2010), 60-77.

4. DirectEDGAR, AcademicEDGAR+ LLC, 2008 North 55 ${ }^{\text {th }}$ Street, Omaha, NE 68104, 2008.

5. Duffie, D, L. Saita and K. Wang, Multi-period Corporate Default Prediction with Stochastic Covariates, Journal of Financial Economics 83, (2007), 635-665.

6. Freed N, and F. Glover, Evaluating Alternative Linear Programming Models to Solve the Two-Group Discriminant Problem, Decision Sciences 17, (1986), 151-162.

7. Grice J. S. and M. T. Dugan, The Limitations of Bankruptcy Prediction Models: Some Cautions for the Researcher, Review of Quantitative Finance and Accounting 17, (2001), 151-166.

8. Grice J. S. and R. W. Ingram, Tests of Generalizability of Altman's Bankruptcy Prediction Model, Journal of Business Research 54, (2001), 53-61.

9. Hammersley, J. S., L. A. Myers, C. Shakespeare, Market Reaction to the Disclosure of Internal Control Weakness and to the Characteristics of Those Weakness under the Section 302 of the Sarbanes Oxley Act of 2002, Review of Accounting Studies, 13(1), (2008), 141-165.

10. Kaiser, H. The Application of Electronic Computers to Factor Analysis, Educational and Psychological Measurement 20, (1960), 141-151

11. Koehler G. J., and S. S. Erenguc, Minimizing Misclassifications in Linear Discriminant Analysis, Decision Sciences 21, (1990), 63-85.

12. Kwak, W., Y. Shi, and G. Kou, Predicting Bankruptcy After The Sarbanes-Oxley Act Using The Most Current Data Mining Approaches, Journal of Business \& Economics Research, 10 (4), (2012),1-10.

13. McKee, T. E. Developing a bankruptcy prediction model via rough sets theory, Intelligent Systems in Accounting, Finance and Management 9,3, (2000).159+.

14. McKee, T. E. Rough sets bankruptcy prediction models versus auditor signaling rates Journal of Forecasting 22. 8, (2003) 569+.

15. Ohlson J., Financial Ratios and the Probabilistic Prediction of Bankruptcy, Journal of Accounting Research 18(1), (1980), 109-131.

16. Peng, Y., G. Kou, G. Wang, H. Wong, and F. Ko, Empirical Evaluation of Classifiers for Software Risk Management, International Journal of Information Technology \& Decision Making, 8(4), (2009), 749-767.

17. Platt, D. H. and M. B. Platt, "Development of a Class of Stable Predictive Variables: The Case of Bankruptcy Prediction," Journal of Business Finance \& Accounting Spring, (1990), 31-51.

18. Sarbanes-Oxley Act (SOX). 2002. Public Law No. 107-204. Washington, D.C.: Government Printing Office.

19. Shumway, T., Forecasting bankruptcy more accurately: A simple hazard model. Journal of Business 74, (2001), 101-124.

20. Solnik, Claude. Small companies push to gain permanent exemption from Sarbanes-Oxley requirements Long Island Business News (Jul 2, 2010).

21. Sun, L. A re-evaluation of auditors' opinions versus statistical models in bankruptcy prediction Review of Quantitative Finance and Accounting 28, 1. (2007). 55-78.

22. Sung, T. K., N. Chang, and G. Lee, Dynamics of Modeling in Data Mining: Interpretive Approach to Bankruptcy Prediction, Journal of Management Information Systems 16(1), (1999), 63-85. 
23. Yip, A. Y. N., Business Failure Prediction: A Case-Based Reasoning Approach, Review of Pacific Basin Financial Markets and Policies 9, 3, (2006), 491-508. 
NOTES 